\title{
Implicit ruminations
}

\author{
ARTHUR S. REBER \\ Brooklyn College and the Graduate Center of the City University of New York, New York
}

\begin{abstract}
Various points of agreement and disagreement with the two target papers are indicated. Support is voiced for Dienes and Berry's (1997) argument that the implicit-explicit dissociation should be determined by invoking subjective criteria and for Neal and Hesketh's (1997) outlining of the problems associated with the very concept of consciousness. However, criticisms are offered for Neal and Hesketh's proffered solution to that problem and their unhappy decision not to include the transfer literature, and for the failure of the authors of both papers to recognize the importance of neurocognitive evidence.
\end{abstract}

Implicit learning (IL) has become a topic of considerable interest these days. Not as intensely studied perhaps as the related problem of implicit memory (see, e.g., Roediger \& McDermott, 1993), but we have passed the time when but a few labored in near isolation. This increased interest has had the expected impact. Some problems that seemed obvious and straightforward have turned out to be more complex and less tractable; others that looked to be potentially important but difficult have revealed themselves to be trivial and uninteresting. This is how the game should be played. The two articles that appear here are examples of the kind of careful assessment needed if we are to get a coherent grip on the larger issue of the acquisition of knowledge and the role that consciousness plays in it.

The early work in IL led to two intriguing suggestions. First, it appeared to be a process whereby knowledge of the underlying structural regularities in a complex stimulus display was acquired largely independently of awareness of what was, in fact, learned (A. S. Reber, 1967). Second, it seemed as though the mental representation of that knowledge was encoded in an abstract form (A. S. Reber, 1969). In the two accompanying pieces, Dienes and Berry (1997) ask hard questions about the former proposition and Neal and Hesketh (1997) review much of the evidence that pertains to the second. Although I have considerable sympathy with both papers and the questions that they pose, my gloss on the literature is not always in concert with that of the authors. But that's why we have forums like this one.

\section{CONSCIOUSNESS}

I like to think about the relationship between learning and consciousness in terms of a continuum. At one pole

This paper was prepared when A.S.R. was a visiting professor at the Department of Psychology, University of Wales, Bangor. Special thanks to Diane Zizak for her help with the final version. Correspondence should be sent to A. S. Reber, Department of Psychology, Brooklyn College of CUNY, 2900 Bedford Ave., Brooklyn. NY I1210 (e-mail: areber@email.gc.cuny.edu) are acquisitional processes that function completely independently of normal states of consciousness and awareness. There are circumstances under which we learn to prefer particular foodstuffs because of their positive postingestive nutritional impact (Sclafani, 1995), and we learn to avoid others because of unhappy gastrointestinal consequences (Braverman \& Bronstein, 1985). Such a process is largely automatic and unintentional; what is required is the proper exposure to appropriate stimuli within particular temporal parameters. Despite the fact that the gut has about the same number of neurons as the spinal cord, top-down factors play little role here. At the other extreme are various actions of memory, problem solving, and reasoning where awareness of action and representation is perhaps the most poignant characteristic of the process. Someone who has learned to solve classic problems like the Tower of Hanoi or work through a logical syllogism is conscious of the process and the solution and can often describe them both quite adequately.

However, for the most part, these are exceptions. Most of the cognitively interesting things that people do involve a delicate blend of the explicit and the implicit, the conscious and the unconscious. Among the many functions of consciousness is the modulation of other processes (see Baars, 1988). That is, consciousness operates as a topdown system that interpenetrates ongoing functions and exerts some measure of control over them. A system bereft of consciousness is one that operates fully automatically.

As one moves along the evolutionary scale, one sees a range of this kind of modulation of function. The less neurologically complex an organism, the more purely its actions are bottom-up. The more complex the organism, the greater the impact of top-down action. In Homo sapiens, the modulating operations reach the full flower of self-reflection and meta-cognitive analysis.

But one of the strongest lessons of evolutionary biology is that forms and functions that are adaptive are not jettisoned. Rather, newer forms and functions are built upon them in ever more complex hierarchical structures. Just because we have evolved powerful and phenomenologically compelling top-down systems does not mean we have disenfranchised the earlier systems that functioned 
independently of reflective modulation. Put simply, the cognitive effectiveness and subjective compellingness of explicit, declarative, conscious processes should not lead us to dismiss the importance of acquisitional systems that operate without benefit of awareness.

If all this is obvious (and I think it is), what impact should such a train of thought have on the manner in which we approach the role of consciousness in the study of complex cognitive processes? Well, one obvious issue is to establish a conceptual cut-point that will allow us to distinguish between processes that are conscious and those that are unconscious. One approach, favored by hardliners such as Brody (1989) and Holender (1986), is to impose a strict criterion that will allow for a clean dissociation between the implicit and the explicit. If, for example, a participant in an experiment performs at chance on a two-alternative forced choice test for recognition of a stimulus but is able to distinguish that stimulus from another along some other dimension (e.g., preference or grammaticality judgments), then and only then should we conclude that there was an implicit, unconscious mental representation of that stimulus.

However, Dienes and Berry (1997), following Merikle (1992), maintain that this is not the psychologically appropriate criterion to use. They opt for a subjective criterion. That is, determine how much knowledge participants actually have $(y)$ and how much they believe they have $(x)$. Whenever $y>x$, the existence of implicitly held knowledge is established. As they note, this is fairly easy to do using confidence estimates. If subjects show abovechance performance on trials where their confidence is at zero, one may safely infer that $y>x$.

A third approach, which Dienes and Berry (1997) are reluctant to endorse, is the free-report method. Here you simply ask your subjects what they know. If their verbal reports do not provide sufficient detail to account for their behavior, it is reasonable to conclude that implicit learning has occurred. Although I have argued in several places (A. S. Reber, 1993b, 1997) that the verbalizability criterion has proven to be a bit of a red herring and that Dienes and Berry's subjective criterion is the most appropriate, I must confess that I have lingering affection for free introspective report.

One of the hallmarks of those most explicit of explicit learning situations noted above is that subjects not only can but also freely do provide verbal expression to their knowledge-and not just to the knowledge of the solution-for they can also tell you about false leads followed and culs de sac that trapped them along the way. IL situations are poignantly different. Subjects are not trying to figure out rules; in fact, such action is often debilitating (A. S. Reber, 1976; Schooler \& Fiore, 1997). They are not testing hypotheses about structure and they are not looking for particular solutions. The role of consciousness is largely absent from the learning process. Note, I am not claiming that consciousness is totally absent. It is not. Subjects are alert and conscious. They are aware that they are engaged in a cognitively complex task.
They know that they are memorizing letter strings or pressing keys or trying to make a computer person act friendly, and if you ask them about these aspects of the experiments they can tell you many interesting things-but little of it is about the underlying structural characteristics of the display that they are learning. There is something special about the phenomenology of implicit tasks and the simple free verbal recall procedure tells you this.

A nice piece of supportive evidence comes from an artificial grammar (AG) learning study by Mathews, Buss, Stanley, Blanchard-Fields, Cho, and Druhan (1989). Over a 4-day period, experimental subjects provided verbal protocols for making grammaticality judgments to groups of yoked controls. Experimental subjects reached asymptote on performance on the second day of the study and showed little improvement after that. However, the yoked groups continued to improve in performance, with those getting Day 4 protocols performing nearly as well as experimental subjects. Subjects continued to improve in their ability to formulate and communicate held knowledge. What they knew implicitly by Day 2 was only slowly and laboriously made explicit by Day 4 . In short, although I agree with Dienes and Berry (1997) that for the most part we are better off using a subjective threshold, I would not want to completely drop the free-articulation criterion. I sense that it has phenomenological importance of which we need to take cognizance.

Part of my defense of this point of view comes from my fascination with the actual "doing" of science and the role that implicit processes likely play in the creative process (A. S. Reber, 1993b). I am not referring to the muchballyhooed incubational phenomena of Kekule or Poincaré (although they are relevant in another context); rather, I am concerned with the laborious and painful manner in which implicitly held knowledge (or what the philosopher/ scientist Michael Polanyi called "personal" knowledge) is made explicit. My own introspective musings suggest that most of my own scientific work takes place by a process of reading, talking, arguing, thinking, worrying, and muttering to myself. Out of this gradually emerges a vague sense of a good experiment to do or an evanescent feeling for the kind of approach to take to a particular problem. The real struggle is to make this knowledge explicit, to articulate the problem, outline the research program, plan the experiment. I suspect that this process is captured in a small way by the findings of Mathews et al. (1989).

\section{ON THE VIABILITY OF THE CONCEPT OF CONSCIOUSNESS}

Neal and Hesketh (1997) put forward the intriguing notion that one reason why IL is controversial "may be that it appears to demonstrate that consciousness does play a functional role in human behavior" (p. 34). They maintain that this proposition presents difficulties because "the goal of cognitive psychology is to provide a computational analysis of mental phenomena. Consciousness is thought to have no role in this analysis, because it is com- 
monly assumed that the phenomenal properties of conscious experience cannot be expressed in computational terms" (p. 34).

This perspective on contemporary cognitive psychology is held by some, to be sure, but I do not think it represents the dominant view. Within philosophical circles there are two positions that reflect, to one degree or another, these sentiments. One is called "eliminative materialism" and is predicated on the assumption that consciousness is best put aside while one is focusing on neuroanatomical and neurocognitive analyses. The other, the one I believe Neal and Hesketh (1997) have in mind, is known as "functionalism," or, more accurately, "hardware-independent functionalism." The presumption here is that the "stuff" the system is made of is irrelevant; computation is all. If, the argument goes, we can work out the computations that underlie cognitive processes, the phenomenal states will be explained in the process. However, in neither of these approaches is consciousness really a nonproblem. Its presumed epiphenomenal status is but a vague hope - and one against which basic principles of evolutionary biology militate. In addition, both are saddled with the emergentist's burden; somehow the proponents are going to have to explain the conditions (neuroanatomical for the eliminative materialists and computational for the functionalists) under which phenomenal states emerge.

In the long run, neither perspective is likely to solve any of the currently existing problems of phenomenal states and their causal properties, and lots of reasons for not being terribly sanguine about either position have been offered (Flanagan, 1992; A. S. Reber, 1996; Searle, 1992). I simply don't think it will work terribly well for us to drop consciousness as a focus of cognitive psychology. George Miller once referred to consciousness as the constitutive problem in psychology and I am largely in agreement. The last time we tried sidestepping consciousness and its various entailments, we had a rather unhappy go of it; it was known as behaviorism.

Hence, I disagree with Neal and Hesketh's (1997) characterization of cognitive psychology. I think consciousness is very much in the center of the topics of surpassing interest. As I and my colleagues have argued on several occasions recently (A. S. Reber, Allen, \& P. J. Reber, in press; A. S. Reber, 1993a; 1997), the reason that IL generates controversy is quite the opposite of what Neal and Hesketh believe. The controversy comes about because the research implies that cognitive operations like induction and abstraction, which many contemporary cognitivists feel lie within the privileged realm of consciousness, may also be expressed in the implicit, unconscious domain. What has exercised the psyches of thinkers such as Dulany (1991, 1997; Dulany, Carlson, \& Dewey, 1984), Perruchet (1994), and Shanks and St. John (1994) is not that abstractive representations can be encoded, but that such encoding might take place independently of consciousness.

Finally in this vein, I am also not particularly optimistic about the prospects of replacing the implicit-explicit dichotomy with one based on intention-nonintention, as Neal and Hesketh (1997) suggest. I appreciate the line of reasoning in which they are engaged, but I fail to see how their proposal is going to solve any problems. Intention is still a function of consciousness, and recasting implicit learning as learning without intention is no more than linguistic sleight of hand. ${ }^{1}$

Consciousness is a messy topic, and, as Neal and Hesketh (1997) point out, we are especially encumbered by the difficulties inherent in finding the cut-point that dissociates conscious from unconscious processes. However, their proffered solutions (focus on computational approaches, replace the notion of consciousness with intention) remind me of the suggestion to the woman who has dropped her keys in the bushes that she search for them under the lamppost where the light is better. If the keys just happen to have bounced over there, it would be great. Alas, they really are under the bushes, in the mud, buried deeply along with lots of other things that look like keys but aren't. We mustn't forget that the human brain is the single most complex entity in our known universe, and the problems of consciousness and how its functions interact with those that operate largely unfettered and unassisted by awareness is going to be one of our thornier problems. Let's just accept the mess ahead of us and get on with the job.

\section{ON REPRESENTATIONAL FORM}

In a recent paper, Lou Manza and I struggled with this issue (Manza \& Reber, in press). Like Neal and Hesketh (1997), we parsed the field of competing theories into two categories, abstractive and episodic. Like Neal and Hesketh, we considered both the holistic episodic theories (Brooks, 1978; Brooks \& Vokey, 1991; Vokey \& Brooks, 1992) and the fragmentary theories (Perruchet, 1994; Perruchet \& Pacteau, 1990). And like Neal and Hesketh, we saw much to support all points of view. However, unlike Neal and Hesketh, we made the transfer studies the central focus and so, perhaps not surprisingly, we came to rather different conclusions.

Neal and Hesketh (1997) state at the outset that they are not going to consider the data from transfer studies because "the limitations of this evidence have been extensively reviewed elsewhere" (p. 24). I think this an unwise decision. As Dienes and Berry (1997) note, the transfer protocol provides the optimum forum for examining the extent to which a particular set of conditions gives rise to representations that are abstract or episodic. Our gloss on the literature (Manza \& Reber, in press) supports the "functionalist" approach first presented nearly 20 years ago (A. S. Reber \& Allen, 1978). That is, both abstract and instance-based representations can emerge from IL situations - it depends on many factors, most significantly the demand characteristics of the learning phase. In Reber and Allen (1978), we showed that when subjects learned the strings generated by an $A G$ in a paired-associates manner, it encouraged the establishment of episodic representations. When an unstructured 
observation technique was used, the tilt was toward abstract encodings. In passing, I should note that we never regarded the paired-associates technique as an "unusual situation" or an "unusual training task," as Neal and Hesketh claim. It is just another way to learn and, like all others, it will have its own particular constraints.

In Manza and Reber (in press), this perspective is reinforced. We present new evidence for both analogical/ episodic and fragmentary/episodic representations and try to show that the circumstances under which the learning takes place go a long way toward determining the kinds and distributions of memorial representations that can be expected. In one of our experiments (which Dienes $\&$ Berry, 1997, cite) we show how easy it is to bias subjects in the direction of more abstract representations simply by having the learning materials instantiated in more than one symbol set. If I have been interpreted as stating that "abstraction is an automatic consequence of attending to any structured stimulus display," as Neal and Hesketh (1997, p. 28) claim, it was unintentional.

Also, Neal and Hesketh's (1997, p. 29) claim that in AG learning studies "subjects who are trained on isolated bigrams perform equivalently to subjects who are given training with the full strings" is not correct. Although it is true that in Perruchet and Pacteau's (1990) original study the bigram-only group performed above chance, they did not perform as well as the full-item group, a finding that has been replicated (Manza \& Reber, in press). More importantly, whatever knowledge bigram-only groups acquire cannot be representationally equivalent to that of the full-item subjects, since the bigram-only subjects do not show transfer to a new stimulus set (Gomez \& Schvaneveldt, 1994; Manza \& Reber, in press).

\section{ON FLEXIBILITY}

One of the central concerns of Dienes and Berry (1997) is the extent to which implicit representations are flexible. It seems clear that they possess some degree of conceptual elasticity, since transfer occurs. However, in every transfer study published, subjects perform better with the nonshifted items, which suggests that these memorial representations may not be all that flexible. This issue, of course, dovetails with the abstract-episodic contrast in that one should reasonably expect abstract representations to be maximally flexible and purely instantiated ones to be considerably less so.

In the study of implicit memory, the evidence favors inflexible representations. Typically, changing the physical form or the manner of presentation of the stimulus fails to produce implicit memory, which has led some (e.g., Dienes and Berry) to generalize that the same may be expected of representations developed in the context of IL situations. However, before accepting fully this line of thinking, it is important to point out the differences between an implicit memory experiment and one on implicit learning. In the former, subjects don't really learn anything new. Rather, previously existing knowledge is activated. That is, if the word alligator is on the original list, the subject's memory consists of this well-known word but with a kind of an episodic tag on it. It is not surprising that implicit memory experiments tend to show relatively inflexible encoding.

In the typical IL experiment, things are not so simple. As noted above, a wide variety of tasks and procedures are in use and each has its own particular demand characteristics. Some of these (Altmann, Dienes, \& Goode, 1995; Manza \& Reber, in press; Mathews et al., 1989) have given strong evidence for highly flexible representations, including those that survive shifts from auditory to visual modality and vice versa. Others (e.g., Wright, 1993) have shown severe reductions in performance under transfer conditions. This is not going to be a simple nut to crack.

An approach that may be helpful is the animal model developed by Eichenbaum and colleagues (Eichenbaum, Mathews, \& Cohen, 1989; Eichenbaum, Otto, \& Cohen, 1992). Because it is possible to measure flexible knowledge using lesion studies, their approach provides an opportunity to expand the study of IL in ways that more traditional experiments cannot. Without going into detail here (see P. J. Reber, Knowlton, \& Squire, 1996), the message of the work of Eichenbaum and others (e.g., Saunders \& Weiskrantz, 1989) is that animals with damage to the medial temporal lobes (MTL) show impaired flexibility compared with controls. Since it is known that animals and humans with MTL damage show virtually normal implicit learning and implicit memory but impaired explicit functioning, the suggestion is that the flexibility needed for transfer may depend on MTL structures that are essential for the formation of explicit memories. Although implicit knowledge, in a pure sense, may be relatively inflexible, in the typical experiment with cortically intact human beings we are dealing with circumstances where both implicit and explicit components are operating synergistically.

\section{WELL, YOU SEE, IT DEPENDS ...}

Both target papers take, to some extent, an "either-or" approach to the issues raised. Neal and Hesketh (1997) are concerned with whether implicitly established representations are abstract or episodic; Dienes and Berry (1997) with whether or not IL is really implicit. Taking such stances reflects standard practice; psychologists just can't seem to resist dichotomies. We like things to be either one way or another. We like to be able to decide that one theory is right and another wrong, that one interpretation of the database captures its nuances and another does not. We seem ineluctably drawn to setting up poles rather than recognizing continua. Alas, this tendency often functions as a hindrance to doing good science. Earlier (A. S. Reber, 1993a, pp. 23ff), I tried to warn against being beguiled by the "polarity fallacy."

[Although] arguments will be put forward to draw distinctions between [implicit and explicit] systems, there will not be any evidence to show that these domains of cognitive 
function should be treated as utterly separable. In fact, there are no reasons, empirical or theoretical, for assuming that there is any well-defined cut-point or threshold separating the two at some point along a continuum.... The interesting psychological issues have to do with balance and not with exclusionary clauses.

I thought that was good advice then and I still do. Implicit learning can yield both abstract and instantiated representations. Implicit learning can take place in a manner that is highly refractory to top-down penetration or it can be relatively easily examined consciously. Although many view the work of Whittlesea and his colleagues (e.g., Whittlesea \& Dorken, 1993) as being critical of our approach, I often find myself in agreement because they try to unpack the conditions under which the varying mental operations become manifest.

\section{SOME FINAL RUMINATIONS}

One of the nice things about a forum like this is that it allows some degree of freedom. Although I have tried to focus on the issues raised by the target articles, I am concerned by the restricted range of issues being discussed. From my perspective, IL is a general process that plays an important role in a wide range of human activity, and to wrap up this commentary, I'd like to briefly run through a number of additional entailments of the work on implicit learning.

1. IL and ontogeny: There are good reasons (see A. S. Reber, 1992) for suspecting that IL abilities change relatively little over the course of development and show less deterioration in an aging population than do explicit learning abilities. There has been very little study of this issue, although it clearly has important implications for theories of cognitive development, pedagogy, and aging. Some related work that is intriguing is that of Haith and his colleagues (Haith, Hazan, \& Goodman, 1988; Haith \& McCarty, 1990), who have shown that infants as young as 3 months learn to anticipate the location of dynamic visual events. Since consciousness emerges only slowly during childhood (Karmiloff-Smith, 1992), this shows that stimulus invariances are picked up easily at very young ages in preconscious humans.

2. IL and individual variation: A parallel line of argument (see A. S. Reber, 1992) leads to the prediction that implicit cognitive functions should show less interindividual variation than explicit cognitive functions and that the implicit should be less concordant with standard measures of intelligence like IQ. Again, although there is little research here, that which has appeared is generally supportive (Mayberry, Taylor, \& O’Brien-Malone, 1995; McGeorge, Crawford, \& Kelly, 1996; Reber, Walkenfeld, \& Hernstadt, 1991).

3. IL and sensorimotor skill: As Wulf and her colleagues have pointed out (Wulf, Lee, \& Schmidt, 1994; Wulf \& Schmidt, in press), much of motor learning is implicit in nature. Masters (1992) showed that implicitly acquired motor skills were dramatically less disrupted by a stressor than were those acquired explicitly, a finding that parallels results from the AG learning literature (A. S. Reber, 1976). However, at this juncture little is known about how motor learning develops and whether or not it makes sense to view it as an analog of the more typically studied cognitive and perceptual domains.

4. IL and neuroanatomy: Seger (1994) suggested that one way to tease apart implicit and explicit functions is to assess how particular behaviors are compromised by neurological injury. Dienes and Berry (1997) examine some of this neurocognitive literature; Neal and Hesketh (1997) ignore it almost completely. Bypassing this issue is even more unfortunate than skipping the transfer issue. If patients who suffer from severe deficits in episodic memory and explicit learning show normal implicit functions, the viability of models based entirely on episodic memorial systems is brought into question. Recently Knowlton and Squire (1994, 1996) showed that amnesics establish abstract memorial representations in AG learning. Interestingly, they also found that when instancebased systems are operative, these patients appear to be more inclined toward fragmentary than toward wholeitem representations.

In a forthcoming paper A. S. Reber, Allen, and J. P. Reber (in press) put forward a somewhat more detailed account of the neuroanatomical distinctions between those systems known to be critical for explicit learning and memory and those suspected of handling the implicit functions. Although it seems clear that damage to the MTL disrupts the explicit, declarative processes of memory and learning but leaves the implicit functions relatively intact, little is known about what neural structures are responsible for the implicit functions and how lesions manifest themselves behaviorally. There is a suggestion (Ungerleider, 1995) that implicit functions may be more intimately tied to the modality of input, which, if correct, would help to explain their relative robustness in the face of neurological insult. The surface has barely been scratched here.

5. IL and preferences: We know that subjects in IL experiments develop preferences for well-structured items over those that violate structure (Gordon \& Holyoak, 1983). Recent work of Manza and his colleagues (Manza \& Bornstein, 1995; Manza, Zizak, \& Reber, in press) has begun to provide some understanding of how implicitly acquired knowledge functions in the formation of preferences and even to get a handle on how our sense of aesthetics might develop. This work clearly is relevant for social psychological issues and may tie in with the parallel research program of Zajonc $(1968,1984)$ on the "mere exposure" effect.

6. IL and philosophy: Finally, I want to draw attention to the intellectual feeding frenzy that has accompanied the reemergence of consciousness as a topic within contemporary philosophy. It is clear that implicit learning and the rest of the cognitive unconscious must be a part of any coherent philosophy of mind, although to date little attention has been allocated to the problem. Recently I tried to address some of these issues (Reber, 1996), but this attempt barely counts as a beginning. 
There is more. I have not mentioned the provocative problems associated with the role of IL in first and second language acquisition (Ellis, 1994) and in the processes of social cognition (Lewicki, 1986; Uleman \& Bargh, 1989). I have skipped discussion of the various classes of formal models that have been proposed, most of which are more powerful and general than Hintzman's (1986), which Neal and Hesketh (1997) favor (Cleeremans, 1993; Dienes, Altmann, \& Gao, in press), of the role of unconscious processing in perception (Reingold \& Merikle, 1988 ), the relationship between emotive states and implicit representations (Rathus, Reber, Manza, \& Kushner, 1994), and the role of attention in IL (Hsiao \& Reber, in press). The quick sketches of problem areas that beckon merely hint at the problems that are entailed by an elaborated theory of IL. Although we still need to struggle with the basic questions of consciousness and representation raised by the target articles, it would be unfortunate if we were to allow ourselves to become bogged down in these debates and fail to explore the many entailments of a sophisticated cognitive unconscious.

\section{REFERENCES}

ALLEN, R., \& ReBER, A. S. (in press). The intelligent unconscious. In W. Bechtel \& G. Graham (Eds.), A companion to cognitive science. London: Blackwell

Altmann, G. T. M., Dienes, Z., \& Goode, A. (1995). On the modality independence of implicitly acquired grammatical knowledge. Journal of Experimental Psychology: Learning, Memory, \& Cognition, 21, 899-912.

BAARS, B. J. (1988). A cognitive theory of consciousness. New York: Cambridge University Press.

Braverman, N. S., \& Bronstein, P. (Eds.) (1985). Experimental as sessments and clinical applications of conditioned food aversions. (Annals of the New York Academy of Sciences, Vol. 443, pp. 1-441). New York: New York Academy of Sciences.

Brody, N. (1989). Unconscious learning of rules: Comment on Reber's analysis of implicit learning. Journal of Experimentol Psychology. General, 118, 236-238.

Brooks, L. R. (1978). Nonanalytic concept formation and memory for instances. In E. Rosch \& B. B. Lloyd (Eds.), Cognition and categorization. New York: Wiley.

BRoOKs, L. R., \& VOKEY, J. R. (1991). Abstract analogies and abstracted grammars: Comments on Reber (1989) and Mathews et al. (1989). Journal of Experimental Psychology: General, 120, 316-323.

Cleeremans, A. (1993). Mechanisms of implicit learning: Connectionist models of sequence processing. Cambridge, MA: MIT Press.

Dienes, Z., Altmann, G. T. M., \& Gao, S.-J. (in press). Mapping across domains without feedback: A neural network model of transfer of implicit knowledge. Cognitive Science.

DienEs, Z., \& BERRY, D. C. (1997). Implicit learning: Below the subjective threshold. Psychonomic Bulletin \& Review, 4, 3-23.

DULANY, D. E. (1991). Conscious representation and thought systems. In R. S. Wyer, Jr., \& T. K. Srull (Eds.), Advances in social cognition (Vol, 4). Hillsdale, NJ: Erlbaum.

Dulany, D. E. (1996). Consciousness in the explicit (deliberative) and implicit (evocative) senses. In J. D. Cohen \& J. W. Schooler (Eds.), Scientific approaches to consciousness (pp. $\mathrm{xx}-\mathrm{xx}$ ). Hillsdale, NJ: Erlbaum.

Dulany, D. E., Carlson, R. A., \& Dewey, G. I. (1984). A case of syntactical learning and judgment: How conscious and how abstract? Journal of Experimental Psychology: General, 113, 541-555.

Eichenbaum, H., Mathews, P., \& Cohen, N. J. (1989). Further studies of hippocampal representation during odor discrimination learn- ing. Behavioral Neuroscience, 103, 1207-1216.

Eichenbaum, H., O'TTO, T., \& COHEN, N. (1992). The hippocampusWhat does it do? Behavioral \& Neural Biology, 57, 2-36.

ELLIS, N. C. (ED.) (1994). Implicit and explicit learning of languages. New York: Academic Press.

Flanagan, O. (1992). Consciousness reconsidered. Cambridge, MA: MIT Press.

GoMez, R. L., \& SCHVANEVELDT, R. W. (1994). What is learned from artificial grammars? Transfer tests of simple association. Journal of Experimental Psychology: Learning, Memory, \& Cognition, 20, 396-410. GORDON, P. C., \& HOLYOAK, K. J. (1983). Implicit learning and generalization of the "mere exposure" effect. Journal of Personality \& Social Psychology, 45, 492-500.

Haith, M. M., Hazan, C., \& Goodman, G. S. (1988). Expectation and anticipation of dynamic visual events by 3.5 -month-old babies. Child Development, 59, 467-479.

HAITH, M. M., \& MCCARTY, M. E. (1990). Stability of visual expectations at 3.0 months of age. Developmental Psychology, 26, 68-74.

Hintzman, D. L. (1986). "Schema abstraction" in a multiple trace memory model. Psychological Review, 93, 411-428.

HOLENDER, D. (1986). Semantic activation without conscious identification in dichotic listening, parafoveal vision, and visual masking: A survey and appraisal. The Behavior \& Brain Sciences, 9, 1-66.

HSIAO, A., \& REBER, A. S. (in press). The role of attention in implicit sequence learning: Theories, findings, and methodological issues. In M. S. Stadler \& P. A. Frensch (Eds.), Implicit learning handbook. Thousand Oaks, CA: Sage.

KARMilloff-SMith, A. (1992). Beyond modularity: A developmental perspective on cognitive science. Cambridge, MA: MIT Press.

KNowlton, B. J., \& SQuire, L. R. (1994). The information acquired during artificial grammar learning. Journal of Experimental Psychology: Learning, Memory, \& Cognition, 20, 79-91.

KNOWLTON, B. J., \& SQUiRE, L. R. (1996). Artificial grammar learning depends on implicit acquisition of both abstract and exemplarspecific information. Journal of Experimental Psychologv: Learning, Memory, \& Cognition, 22, 169-181.

LEWICKI, P. (1986). Nonconscious social information processing. New York: Academic Press.

Manza, L., \& Bornstein, R. F. (1995). Affective discrimination and the implicit learning process. Consciousness \& Cognition, 4, 399-409.

MANZA, L., \& Reber, A. S. (in press). Representation of tacit knowledge: Transfer across stimulus forms and modalities. In D. C. Berry (Ed.), How implicit is implicit learning? New York: Oxford University Press.

MANZA, L., ZiZAK, D., \& Reber, A. S. (in press). Emotional preference tasks and the implicit learning process. In M. S. Stadler \& P. A. Frensch (Eds.), Implicit learning handbook. Thousand Oaks, CA: Sage.

MAsters, R. S. W. (1992). Knowledge, knerves, and know-how: The role of explicit versus implicit knowledge in the breakdown of a complex motor skill under pressure. British Journal of Psvchology, 83, 343-358.

Mathews, R. C., Buss, R. R., Stanley, W. B., Blanchard-Fields, F., Cho, J.-R., \& Druhan, B. (1989). The role of implicit and explicit processes in learning from examples: A synergistic effect. Journal of Experimental Psychology: Learning, Memony, \& Cognition, 15, 1083 1100.

Mayberry, M., Taylor, M., \& O'Brien-Malone, A. (1995). Implicit learning: Sensitive to age but not IQ. Australian Journal of Psychology, 47, 8-17.

MCGeorge, P., Crawford, J. R., \& Kell.y, S. W. (1996). The relationships between psychometric intelligence and learning in an explicit and implicit task. Manuscript submitted for publication.

MerikLE, P. M. (1992). Perception without awareness: Critical issues. American Psychologist, 47, 792-795.

Neal, A., \& Hesketh, B. (1997). Episodic knowledge and implicit learning. Psychonomic Bulletin \& Review, 4, 24-37.

Perruchet, P. (1994). Learning from complex rule-governed environments: On the proper functions of nonconscious and conscious processes. In C. Umiltà \& M. Moscovitch (Eds.), Attention and performance $X V$ : Conscious and unconscious information processing (pp. 811-836). Cambridge, MA: MIT Press. 
Perruchet, P., \& Pacteau, C. (1990). Synthetic grammar learning: Implicit rule abstraction or explicit fragmentary knowledge? Journal of Experimental Psychology: General, 119, 264-275

RaThus, J., Reber, A. S., MANZA, L., \& KuShner, M. (1994). Implicit and explicit learning: Differential effects of affective states. Perceptual \& Motor Skills, 79, 163-184.

REBER, A. S. (1967). Implicit learning of artificial grammars. Journal of Verbal Learning \& Verbal Behavior, 77, 317-327.

REBER, A. S. (1969). Transfer of syntactic structure in synthetic languages. Journal of Experimental Psychology, 81, 115-119.

REBER, A. S. (1976). Implicit learning of synthetic languages: The role of instructional set. Journal of Experimental psychology: Human Learning \& Memory, 2, 88-94.

ReBER, A. S. (1992). The cognitive unconscious: An evolutionary perspective. Consciousness \& Cognition, 1, 93-133.

ReBer, A. S. (1993a). Implicit learning and tacit knowledge: An essay on the cognitive unconscious. New York: Oxford University Press.

Reber, A. S. (1993b). Personal knowledge and the cognitive unconscious. Polanyiana, 3, 97-115.

REBER, A. S. (1996, April). Caterpillars and consciousness. Paper presented at a meeting of the British Psychological Society, Brighton.

REBER, A. S. (1997). How to differentiate implicit and explicit modes of acquisition. In J. D. Cohen \& J. W. Schooler (Eds.), Scientific ap proaches to consciousness (pp. 137-160). Hillsdale, NJ: Erlbaum.

Reber, A. S., \& AlLEN, R. (1978). Analogy and abstraction strategies in synthetic grammar learning: A functionalist interpretation. Cognition, 6, 189-221.

Reber, A. S., Allen, R., \& Reber, P. J. (in press). Implicit and explicit learning. In R. Sternberg (Ed.), The concept of cognition. Cambridge, MA: MIT Press.

Reber, A. S., Walkenfeld, F. F., \& Hernstadt, R. (1991). Implicit and explicit learning: Individual differences and IQ. Journal of Experimental Psychology: Learning. Memory, \& Cognition, 17, 888-896.

REBER, P. J., KNowlton, B. J., \& SQuiRe, L. (1996). Dissociable properties of memory systems: Differences in the flexibility of declarative and nondeclarative knowledge. Behavioral Neuroscience, 110, 861-871.

ReINGOLD, E. M., \& MERIKLE, P. M. (1988). Using direct and indirect measures to study perception without awareness. Perception \& Psychophysics, 44, 563-575.

RoEDiger, H. L., III, \& MCDERmott, K. B. (1993). Implicit memory in normal human subjects. In F. Boller \& J. Grafman (Eds.), Handbook of neuropsychology (Vol. 8, pp. 61-131). New York: Elsevier.

Saunders, R., \& Weiskrantz, L. (1989). The effects of fornix transection and combined fornix transection, mammillary body lesions and hippocampal ablations on object-pair association memory in the rhesus monkey. Behavioral \& Brain Research, 35, 85-94.

SCHOOLER, J. W., \& Fiore, S. M. (1996). Consciousness and the limits of language: You can't always think what you say or say what you think. In J. D. Cohen \& J. W. Schooler (Eds.), Scientific approaches to consciousness (pp. 241-260). Hillsdale, NJ: Erlbaum.

SCLAFANI, A. (1995). How food preferences are learned-laboratory animal models. Proceedings of the Nutrition Society, 54, 419-427.

SEARLE, J. (1992). The rediscovery of the mind. Cambridge, MA: MIT Press.

SEgER, C.A. (1994). Implicit learning. Psychological Bulletin, 115, 163-196.

Shanks, D. R., \& ST. JoHN, M. F. (1994). Characteristics of dissociable human learning systems. Behavioral \& Brain Sciences, 17, 367-448.

Uleman, J. S., \& Bargh, J. A. (1989). Unintended thought. New York: Guilford.

UNGERLEIDER, L. G. (1995). Functional brain imaging studies of cortical mechanisms for memory. Science, 270, 769-775.

VoKey, J. R., \& Brooks, L. R. (1992). Salience of item knowledge in learning artificial grammars. Journal of Experimental Psychology: Learning, Memory, \& Cognition, 18, 328-344.

Whirtlesea, B. W. A., \& DORKEN, M. D. (1993). Incidentally, things in general are particularly determined: An episodic-processing account of implicit learning. Journal of Experimental Psychology: General, 122, 227-248.

WRIGHT, R. (1993, July). The role of "explicit" variables on artificial grammar learning. Paper presented at the third annual meeting of the Canadian Society for Brain, Behaviour, and Cognitive Science and the Experimental Psychology Society, Toronto.

Wulf, G., LeE, T. D., \& Schmidt, R. A. (1994). Reducing knowledge of results about relative versus absolute timing: Differential effects on learning. Journal of Motor Behavior, 26, 362-369.

WULF, G.. \& SCHMIDT, R. A. (in press). Variability of practice and implicit motor learning. Journal of Experimental Psychology: General.

ZAJONC, R. B. (1968). Attitudinal effects of mere exposure. Journal of Personality \& Social Psychology Monograph Supplement, 9(2), 1-27.

ZAJONC, R. B. (1984). On the primacy of affect. American Psychologist, $39,117-123$.

\section{NOTE}

1. Neal and Hesketh's (1997) argument seems close to that recently put forward by Dulany (1996), who based his distinction on what he calls "deliberative" and "evocative" functions. However, Dulany does not want to cut consciousness out of the deal; he merely wants to recast the problem of implicit learning into one that can be tucked under his general top-down system.

(Manuscript received August 8, 1996; revision accepted for publication October 9,1996 .) 